\title{
O que é a escola a partir do sentido construído por alunos
}

\author{
Patrícia Batista Marques \\ Marisa Irene Siqueira Castanho
}

\begin{abstract}
Resumo
Esta pesquisa insere-se na área da Psicologia Escolar e Educacional e investiga o sentido atribuído à escola por alunos. Trata-se de uma pesquisa participante, com observações de campo, entrevistas e produções diversificadas, com sujeitos de 10 a 13 anos, do Ensino Fundamental II de escolas públicas, realizada no espaço de um projeto de educação não formal, em comunidade da periferia de São Paulo. Pela análise qualitativa, construíram-se núcleos de significação referentes a: visão geral da escola; finalidade da escola; cotidiano escolar; agentes institucionais; condições sociais; pais; sociedade. Os resultados mostram que a escola é importante, sendo promessa de um futuro digno, mas é vivida cotidianamente com aprendizagens não satisfatórias, aulas sem sentido, aulas vagas, relações interpessoais desrespeitosas, percepção de desinteresse público e sensação de cansaço de alunos e professores. Este estudo confirma que, embora valorizada socialmente, a escola mostra dificuldades de cumprir seu papel, segundo os sujeitos da pesquisa.
\end{abstract}

Palavras-chave: Psicologia Escolar, Psicologia Social, sentido da escola para o aluno.

\section{The school from students point-of-view}

\begin{abstract}
In this study we investigate the meaning attributed to school by students. This is a participatory research, with field investigation, interviews and diversified activities, with students of public school from 10 to 13 years, in fundamental education. We conducted our study within a non-formal educational context in a peripheral community in São Paulo. By using the qualitative analysis it was possible to build up signification nuclei related to a general overview of the school, such as: purpose of the school; school routine; institutional agents; social conditions; parents; society and so on. The results show that school is important as it provides the students with a prospect for a dignified future. However, it reflects an everyday non-satisfying learning, meaningless classes; lack of classes; disrespectful interpersonal relationships; perception of public disinterest; feeling of tiredness lived by teachers and students. This study confirms that, although valued socially, the school shows difficulties fulfilling its role, according to student's perception.
\end{abstract}

Keywords: School psychology, social psychology, sense of school by students.

\section{Qué es la escuela, a partir del sentido construido por alumnos}

\section{Resumen}

Este estudio se sitúa en el área de Psicología Escolar y Educacional e investiga el sentido atribuido a la escuela por alumnos. Se trata de una investigación participante, con observaciones de campo, entrevistas y diversas producciones, con sujetos de 10 a 13 años, de la Enseñanza Primaria II de escuelas públicas, realizada en proyecto de educación no-formal, en comunidad de la periferia de São Paulo. Por medio de análisis cualitativo se construyeron núcleos de significación referentes a: visión general de la escuela; finalidad de la escuela; cotidiano escolar; agentes institucionales; condiciones sociales; padres; sociedad. Los resultados muestran que la escuela es importante, por ser promesa de futuro digno, sin embargo se vive un cotidiano con aprendizajes no satisfactorios; clases sin sentido; clases sin profesor; sin respeto en las relaciones interpersonales; percepción de la falta de interés público; sensación de cansancio de alumnos y profesores. Esta investigación confirma, según los sujetos del estudio, que, aunque valorizada socialmente, la escuela muestra dificultades de cumplir su papel.

Palabras Clave: Psicología, psicología social, sentido de la escuela para el alumno. 


\section{Introdução}

A escola, nas sociedades letradas como a nossa, ocupa lugar por excelência para que se cumpram as funções da educação e da aprendizagem dos conhecimentos, das artes, das ciências e da tecnologia. As psicologias que emergiram no início do século $X X$ enfatizavam, cada uma a seu modo, a importância dos processos de aprendizagem e de ação do meio externo no desenvolvimento das crianças, na clássica discussão a respeito da natureza e do ambiente como fatores determinantes desse desenvolvimento. Dentre os teóricos, destaca-se Vigotski $(1998 b)^{1}$, para quem a escola tinha papel fundamental ao produzir "algo fundamentalmente novo do desenvolvimento da criança" (p. 110) na direção dos processos psicológicos superiores e da entrada da criança em um meio mediatizado pela cultura e pela linguagem.

As ideias de Vigotski tiveram penetração nos meios acadêmicos no Brasil com a constituição, a partir da década de 1980, de vários grupos de pesquisadores interessados na construção de novas bases epistemológicas para a Psicologia (Bock, Gonçalves, \& Furtado, 2001; Lane \& Camargo, 1995; Ozella \& Sanchez, 2002) e no desenvolvimento do pensamento educacional (Davis \& Silva, 2004; Freitas, 2000).

Naquele momento, a leitura social, histórica e cultural do desenvolvimento do pensamento e da consciência introduziu novas possibilidades de compreensão do homem como um ser ativo no próprio desenvolvimento, produtor e produto das relações sociais vividas. Tais ideias encontraram um campo fértil a partir de outras advindas do campo da Sociologia da Educação a respeito de uma visão crítica da escola e das relações entre educação escolar e valores hegemônicos comprometedores do trabalho pedagógico (Bourdieu, 1972, 1966/1999; Bourdieu \& Champagne, 1992/1999; Snyders, 1981), bem como de uma leitura dos espaços institucionais, das relações e dos conflitos nem sempre explicitados que circunscrevem a malha onde os processos educativos se dão (Althusser, 1974; Bleger, 1966, 1976; Lapassade, 1977).

Essas reflexões estiveram presentes no longo período de expansão do sistema educacional brasileiro, que teve início a partir da década de 1950 e 1960, culminando na implantação dos ciclos básicos na década de $1980^{2}$. Tal medida no âmbito das políticas públicas foi adotada com o intuito de

\footnotetext{
1 Referimo-nos, em especial, ao texto "Interação entre aprendizado e desenvolvimento", publicado no Brasil no livro A formação social da mente pela Editora Martins Fontes, em seis edições, a partir de tradução do inglês de uma coletânea de ensaios publicados após a morte de Vygotsky, em 1935, intitulada "O Desenvolvimento Mental das Crianças e o Processo de Aprendizado", de acordo com Michael Cole e cols. no prefácio da $6^{\mathrm{a}}$ edição (1998b, p. XIV).

2 Ciclo básico de alfabetização adotado em São Paulo (1984) e em Minas Gerais (1985); expansão dessas medidas em outros Estados e municípios; e uma segunda geração dessas inovações, tendo como ponta a Escola Plural de Belo Horizonte e a educação continuada no estado de São Paulo, estas últimas fundamentadas na Lei de Diretrizes e Bases de 1996, que "abrigou as experiências anteriores e abriu caminho para outras inovações" (conforme Gomes, 2004, p. 39).
}

corrigir distorções quanto à qualidade do ensino na escola pública, em especial as relacionadas aos mecanismos de seletividade que entravam em choque com a possibilidade de sucesso escolar das novas camadas no interior da escola, levando às múltiplas repetências e à evasão escolar de grande contingente da população (Mello, 1979, 1981).

Pesquisas (Ferrari, 1999a, 1999b; Gomes, 2002, 2004; Mainardes, 1998, 1999) mostram que houve, como decorrência dessas iniciativas, um aumento substancial do acesso da população em idade escolar à escola, expansão das vagas e progressiva correção de fluxo. No entanto, as mesmas pesquisas trazem elementos para a discussão da baixa qualidade do ensino da população e a não conclusão do ciclo fundamental de oito anos para cerca de 2/3 da população de 15 anos ou mais (Ferrari, 1999b), ou dos equívocos e distorções na implantação das medidas e na coexistência de uma "escola velha" ao lado de uma "escola nova" (Gomes, 2004). As soluções para tais distorções dependem, segundo os pesquisadores, de investimento e alocação adequada de recursos, de trabalho de efetiva formação dos educadores e do envolvimento de todos os sujeitos na ação educativa.

No que tange especificamente à educação de crianças e jovens oriundos das classes populares, a revisão da literatura aponta um volume muito grande de contribuições acerca das relações entre pobreza e baixo rendimento escolar e da tendência equivocada de se considerar como natural o fracasso dessa população com base em considerações como marginalização, carência cultural, desestruturação das famílias, baixas habilidades cognitivas e despreparo social (Bourdieu, 1999; Bourdieu \& Champagne, 1999; Cagliari, 1997; Campos, 2003; Lahire, 1997; Patto, 1981, 1984, 1990; Sawaia, 2002).

Os autores sugerem que o foco seja recolocado na análise complexa da exclusão, que "no caso especial da educação envolve fortes aspectos simbólicos, incluindo o como é vivida e representada a experiência da exclusão" (Campos, 2003, p. 186), uma vez que o que está em jogo não é a pobreza, mas a permanência das condições de desigualdade no interior da escola (Bourdieu \& Champagne, 1999; Patto, 1990).

O levantamento bibliográfico na área da Psicologia Escolar e Educacional leva a uma intensa produção de trabalhos e textos publicados em periódicos, livros, dissertações e teses sobre a questão da escola e a produção do fracasso escolar, encabeçados por obras pioneiras como as de Patto $(1981,1984)^{3}$. A estreita relação entre o objeto de estudo e o campo de atuação profissional levou a Psicologia a um questionamento das interpretações psicologizantes do fracasso escolar e a um amadurecimento da produção

\footnotetext{
3 As obras constantemente citadas são Introdução à Psicologia Escolar, de Maria Helena de Souza Patto, inicialmente editada em 1981 e várias vezes reeditada. Trata-se de uma coletânea de diferentes autores que discutem o fracasso escolar, suas causas, algumas explicações e seus contextos. E Psicologia e ideologia, editada em 1984, em que a autora explicita o movimento de crítica à Psicologia da Educação e a conivência de uma Psicologia acrítica na explicação do fracasso escolar por fatores individuais do aluno, de personalidade, de inteligência e de comportamento, entre outros.
} 
científica a partir de uma reflexão crítica sobre a realidade social e educacional e dos determinantes sociais e históricos na produção do fracasso escolar e na base dos processos de exclusão.

São inúmeros os pesquisadores que têm se sucedido nos trabalhos voltados para uma análise crítica da escola no sistema educacional brasileiro, bem como da educação e das relações entre Psicologia e Educação, não sendo possível esgotar o assunto neste trabalho, o que demandaria outro texto. No entanto, é importante ressaltar que produções mais recentes na área da Psicologia Escolar e Educacional (Gatti, 2004; Marinho-Araújo e cols., 2009; Meira \& Antunes, 2003; Oliveira, Souza, \& Rego, 2002; Tanamachi, Souza, \& Rocha, 2002) continuam focalizando a deficiência da escola para lidar com a diversidade e as diferenças, o que resulta em um desencontro entre agentes e usuários, entre o professor e o aluno. Tais estudos sugerem que ainda há uma resistência da escola em relação aos alunos das camadas populares, o que suscitou o interesse em conhecer sobre como os alunos reagem e como se relacionam com a escola.

Em busca de respostas para essas questões, este estudo teve por objetivo investigar o sentido construído por alunos da rede pública do Ensino Fundamental II às diferentes escolas por eles frequentadas.

A partir de uma visão social e crítica do desenvolvimento humano, em especial a teoria sócio-histórica de Vigotski (1998a, 1998b), entende-se que o ambiente, ao oferecer tarefas de ingresso ao mundo cultural, profissional e social, provoca o desenvolvimento das crianças em direção a estágios mais elevados, sendo a intervenção pedagógica fundamental para provocar os avanços que não ocorreriam espontaneamente.

A complexa relação entre desenvolvimento psicológico e escolarização é tema tratado em alguns trabalhos a partir dos textos de Vigotski, destacando-se aqui, para nossa reflexão, o de Kohl (1996). Para a autora, a escola promove saltos qualitativos em direção à inserção social e cultural dos sujeitos escolarizados quando comparados ao não escolarizados. Isso, no entanto, não significa que tais indivíduos sejam mais capacitados intelectualmente, mas tão somente que estão mais bem instrumentados e habilitados para o enfrentamento das demandas que se impõem nas sociedades complexas como a nossa. Nesse sentido, "a exclusão do processo de escolarização, bem como quaisquer formas de empobrecimento da experiência escolar, estariam, portanto, deixando de promover o acesso do indivíduo a dimensões fundamentais de sua própria cultura" (Kohl, 1996, p. 101).

Vigotski (1998b) atribui à atividade prática do homem no mundo um poder de atividade simbólica e organizadora por meio de signos e instrumentos. É na atividade prática no mundo, na relação entre os homens que ocorrem os processos de desenvolvimento e de mudança da realidade tanto objetiva como subjetiva. É por meio de processos mediadores sociais e instrumentais que os significados vão sendo internalizados, modificados, e os sentidos vão sendo produzidos a partir das experiências individuais coletivamente partilhadas.
O sentido é o termo proposto por Vigotski (1998a) como um dos componentes da palavra, a qual possui dois componentes, o significado propriamente dito e o sentido. Significado refere-se ao sistema de relações objetivas oriundas do processo de desenvolvimento da palavra, um núcleo relativamente estável de compreensão da palavra compartilhado por todas as pessoas que a utilizam. Já o sentido refere-se ao significado da palavra para cada indivíduo, composto por relações que dizem respeito ao contexto de uso da palavra e às vivências afetivas do indivíduo.

Aguiar (2002) afirma que, para compreender a fala de alguém e entender suas palavras, é necessário entender seu pensamento (que é sempre emocionado) e a apreensão do significado da fala, pois o significado, além de parte integrante da palavra, é simultaneamente ato do pensamento, unidade do pensamento e da linguagem.

Já que o significado contém as propriedades do pensamento, por meio da palavra, podemos apreender os aspectos cognitivos-afetivos-volitivos que constituem a subjetividade.

A fala, construída na relação com a história e a cultura e expressa pelo sujeito, corresponde à maneira como este é capaz de expressar/codificar, neste momento específico, as vivências que se processam em sua subjetividade; cabe ao pesquisador o esforço analítico de ultrapassar essas aparências (formas de significação) e ir em busca das determinações (históricas e sociais), que se configuram no plano do sujeito como motivações, necessidades, interesses (que são, portanto, individuais e históricos), para chegar ao sentido atribuído/constituído pelo sujeito (Aguiar, 2002, p. 131).

Assim, o significado é mediado por algo mais amplo: o sentido, que é a articulação de todos os eventos psicológicos que a palavra desperta em nossa consciência (Aguiar, 2002).

\section{Método}

Partindo desses pressupostos e visando compreender, conforme já descrito, o sentido construído pelos alunos a respeito da escola, esta pesquisa pretendeu uma abordagem empírica, em que a escuta estivesse aberta aos educandos.

Por que escutar os alunos? Porque assim seria possível remeter-se àqueles diretamente implicados na situação objeto de estudo. Além do mais, um levantamento bibliográfico indicou serem pouco usuais pesquisas voltadas à escuta dos alunos.

Uma variedade de recursos, como entrevistas individuais e coletivas, desenhos, colagens, frases incompletas e questionários, oportunizou diferentes formas de expressão, tendo em Rey (2002) um importante suporte metodológico, para quem a construção do conhecimento na pesquisa qualitativa é sempre uma produção construtiva-interpretativa. 
As diferentes formas de representar as vivências, ideias e sentimentos em relação à escola possibilitaram levantar indicadores que, por meio da análise de conteúdo (Bardin, 1977), levaram à organização de categorias temáticas sobre a visão geral da escola, sua finalidade, como seria não ir à escola, evocações, o cotidiano escolar e as práticas educativas, os agentes institucionais (o professor, o diretor, o inspetor e o próprio aluno), a visão dos pais e colegas sobre a escola e as condições sociais que permeiam a escola. Uma vez organizados esses conteúdos de uma forma mais objetivada, procedeu-se a "uma articulação de conteúdos semelhantes, complementares ou contraditórios" com vistas "a verificar as transformações e contradições que ocorrem no processo de construção dos sentidos e dos significados" (Aguiar \& Ozella, 2006, p. 233-234), o que possibilita ir mais além dos indicadores e integrá-los em um processo de interpretação por núcleos de significação.

A pesquisa desenvolveu-se no espaço de um projeto social de educação não formal da comunidade de Heliópolis, bairro periférico que constitui a maior favela da cidade de São Paulo ${ }^{4}$. O contexto social onde o projeto se insere apresentava as seguintes características, de acordo com dados do Instituto Brasileiro de Geografia e Estatística (2000) e da Prefeitura Municipal de São Paulo (2003): alto índice de analfabetismo; renda média familiar em torno de $\mathrm{R} \$ 250,00^{5}$; baixa escolarização da população, com média de quatro anos de escola; população predominante de migrantes nordestinos e seus descendentes, com baixa qualificação profissional; população de jovens acima da média da população de São Paulo.

A população específica atendida no projeto era de cerca de 250 crianças e adolescentes na faixa etária de 7 a 14 anos, cujas famílias tinham como expectativa em relação ao projeto a complementação escolar, o acompanhamento da lição de casa e a proteção na ausência dos pais contra os riscos do contato com as drogas, com a sexualidade precoce e o envolvimento com atividades ligadas ao tráfico. A escolha desses alunos como participantes deste estudo justifica-se pelo fato de estarem reunidos, em um único local, crianças e adolescentes de 23 escolas públicas da abrangência. Não devemos julgar que as dificuldades com relação ao ensinoaprendizagem e à relação aluno-escola sejam restritas aos alunos do ensino público. No entanto, é a rede pública que atende uma parcela majoritária da população, em especial a que vive em situação de vulnerabilidade social para quem a escola é referência fundamental para o acesso no mundo social, cultural e do trabalho.

A pesquisa foi realizada na oficina de orientação de estudos, destinada à realização da lição de casa escolar. Este foi o espaço escolhido, pois fazia uma ponte com a escola, facilitando o desencadear de conversas sobre ela.

4 Ressalta-se que há um consentimento formal da instituição e dos participantes quanto à publicação dos resultados desta pesquisa. 5 Valor do salário mínimo nacional, segundo fonte do DIEESE, de $\mathrm{R} \$ 200,00$ correspondentes a menos de 100 dólares e valor da cesta básica, de $70,53 \%$ do valor do salário mínimo. Fonte: http:// www.condsef.org.br/links_f_ut_dieese.htm. Acesso em 29/10/2008.
Participaram da pesquisa 23 crianças e adolescentes do Ensino Fundamental II, com idades entre 10 e 13 anos, que frequentavam o projeto pela manhã e iam para a escola à tarde, sendo 12 meninas e 11 meninos que cursavam a $5^{a} \mathrm{e}$ a $6^{a}$ série, em sua maioria, e nenhum referiu histórico de repetência. É importante ressaltar que, na análise, foi mantido o linguajar próprio dos sujeitos, sem correção gramatical.

\section{Resultados e Discussão}

O contato com o campo foi receptivo, desde as coordenadoras do projeto e da educadora até as crianças e adolescentes. As atividades propostas foram semanais e ocuparam uma parte do horário, de maneira a permitir que eles fizessem as tarefas planejadas da oficina. Sempre houve colaboração e participação das crianças e adolescentes. O contato prolongado com o campo permitiu a criação de um laço de afeição dos participantes junto à pesquisadora, o conhecimento pelo nome e a interação.

Dos 23 participantes, 13 estavam com 11 e 12 anos, frequentando a $5^{\mathrm{a}}$ série; sete, com 12 e 13 anos, na $6^{\mathrm{a}}$ série; um, com 12 anos, na $4^{a}$ série; e uma menina, com 10 anos, com necessidades especiais, por ser surda-muda, na $4^{\mathrm{a}}$ série. Embora se constate certo atraso na relação idade/ série, não houve relato de repetência. A maioria dos pais era proveniente da região Nordeste (11 pais e 19 mães); tinham idades entre 31 e 40 anos; quatro eram semianalfabetos, 19 cursaram o ensino fundamental, 15, o ensino médio, um, o curso superior e oito não souberam informar o nível de escolaridade dos pais. As profissões dos pais variavam entre pedreiro, motorista, gráfico, padeiro, marceneiro e metalúrgico, e as mães eram domésticas, costureiras e do lar. O perfil das famílias sugere uma tendência a um nível mais elevado de escolarização dos pais, para além dos quatro anos de escola, de acordo com a caracterização das famílias do bairro.

Os conteúdos apreendidos a partir dos diferentes momentos e atividades foram organizados da seguinte maneira: levantamento de indicadores (palavras, expressões verbais) por frequência de aparecimento (repetição ou reiteração); agrupamento por categorias temáticas; e integração pelo processo de articulação dos conteúdos (por semelhança, complementaridade, contradição) na construção de núcleos de significação.

No quadro 1, apresentam-se os dados agrupados na categoria temática denominada Visão Geral da Escola.

A visão geral da escola para os alunos se constitui a partir da aglutinação de expressões variadas e de diferentes formas de olhar a escola. Destaca-se, em 47 indicadores, a crítica à escola, dizem que a escola é ruim, apontam os defeitos, classificam-na como insatisfatória. A fala a seguir é indicativa desta visão negativa generalizada a respeito da escola:

Essas escolas de hoje em dia não presta pra nada... nada; não tem nada que preste, é muita bagunça. 
Quadro 1. Visão geral da escola.

\begin{tabular}{|l|l|c|}
\hline Núcleos de significação & Indicadores & N \\
\hline $\begin{array}{l}\text { Negatividade e crítica em } \\
\text { relação à escola }\end{array}$ & $\begin{array}{l}\text { Insatisfação quanto à escola e reconhecimento de } \\
\text { dificuldades que ela apresenta (ruim, muito ruim, } \\
\text { insatisfatória, uma porcaria) }\end{array}$ & 47 \\
\hline $\begin{array}{l}\text { Contradição quanto à po- } \\
\text { sitividade/negatividade da } \\
\text { escola }\end{array}$ & $\begin{array}{l}\text { Satisfação com restrições (mais ou menos boa, } \\
\text { boa com restrições, tem dia que é boa, tem dia } \\
\text { que é ruim) }\end{array}$ & 30 \\
\hline $\begin{array}{l}\text { Positividade em relação à } \\
\text { escola }\end{array}$ & $\begin{array}{l}\text { Satisfação quanto à escola e reconhecimento do } \\
\text { seu valor (boa, muito boa, satisfatória, importante, } \\
\text { não poderia viver sem ela) }\end{array}$ & 17 \\
\hline $\begin{array}{l}\text { Ausência de sentido ou } \\
\text { indiferença }\end{array}$ & $\begin{array}{l}\text { A escola como lugar de objetos e carteiras; nada a } \\
\text { declarar; indiferença }\end{array}$ & 13 \\
\hline
\end{tabular}

Quadro 2. Finalidade da escola.

\begin{tabular}{|l|l|c|}
\hline $\begin{array}{l}\text { Núcleos de significação da } \\
\text { finalidade da escola }\end{array}$ & Indicadores & N \\
\hline $\begin{array}{l}\text { Positiva relacionada à apren- } \\
\text { dizagem }\end{array}$ & $\begin{array}{l}\text { Para aprender (matérias em geral, ler e escrever, } \\
\text { fazer conta e troco, a trabalhar) }\end{array}$ & 80 \\
\hline $\begin{array}{l}\text { Positiva relacionada à obten- } \\
\text { ção de emprego e melhores } \\
\text { condições }\end{array}$ & $\begin{array}{l}\text { Para conseguir emprego (saber trabalhar, ter uma } \\
\text { formação profissional) }\end{array}$ & 18 \\
\hline Negativa & Para nada, para falir os alunos & 3 \\
\hline $\begin{array}{l}\text { Positiva relacionada à sociali- } \\
\text { zação secundária }\end{array}$ & Para fazer amigos & 1 \\
\hline
\end{tabular}

Muitos outros (30 indicadores) constroem um núcleo de significação da contradição entre a positividade e a negatividade:

Sim [estou satisfeito], mas acho que poderia aprender mais mudando de escola.

Alguns, mesmo que em menor número (17 indicadores) mostram-se satisfeitos com a escola, veem que a escola é boa e a valorizam como algo importante em suas vidas:

A escola pra mim é uma luz no fim do túnel e, sem a escola, eu não saberia o que eu seria...

Por último, 13 indicadores denotam a indiferença:

NDA. Sei lá, mano. ND, nada a declarar. Não significa nada. Escola... normal.

A contradição é visível em suas falas, sobressaindo as expressões relativas à insatisfação dos sujeitos quanto à escola que frequentam, o que permite apreender que a escola não atende às suas expectativas, sendo alvo de críticas, de raiva, de descaso ou desconsideração.
No quadro 2, apresentam-se os indicadores agrupados em torno da categoria temática Finalidade da Escola, ou seja, para que ela serve, na visão dos participantes.

Para a maioria (80 indicadores), a finalidade da escola é o aprendizado. Esse resultado contrasta com o número reduzido de indicadores com significações positivas em relação à escola no quadro anterior. Há uma presença significativa (18 indicadores) de referências à possibilidade de colocação no mercado de trabalho e preparo para a profissionalização.

Tais respostas ligadas à escola como sendo local de aprendizagem e de formação qualificada indicam a possibilidade de superação das condições concretas vividas no cotidiano pauperizado em que se encontram os participantes da pesquisa, a exemplo de uma das falas:

Nós vai ter um serviço muito bom, pra gente não precisar ficar catando papelão, é... garrafa, latinha, não precisar ficar levando essas carroças, né?.

Ou seja, parece estar presente uma visão ideologizada da escola como salvadora, carregada da distinção presente no imaginário social de que há um diferencial em relação a quem não a frequenta. No entanto, o conjunto de 
Quadro 3. Como seria não ir à escola.

\begin{tabular}{|l|l|c|}
\hline $\begin{array}{l}\text { Núcleos de significação } \\
\text { sobre a possibilidade de } \\
\text { não ir à escola }\end{array}$ & Indicadores & N \\
\hline $\begin{array}{l}\text { Positiva com significação } \\
\text { negativa }\end{array}$ & $\begin{array}{l}\text { Seria bom ou quase bom não ir à escola (legal, } \\
\text { bom, muito legal, mais ou menos bom) }\end{array}$ & 12 \\
\hline $\begin{array}{l}\text { Negativa com significação } \\
\text { positiva }\end{array}$ & $\begin{array}{l}\text { Não seria bom não ir à escola (ruim, péssimo, } \\
\text { chato, prejudicial) }\end{array}$ & 12 \\
\hline
\end{tabular}

Quadro 4. Evocações sobre a escola.

\begin{tabular}{|l|l|c|}
\hline $\begin{array}{l}\text { Núcleos de significação a } \\
\text { partir das evocações sobre } \\
\text { a escola }\end{array}$ & Indicadores & N \\
\hline $\begin{array}{l}\text { Fracasso e sentimento de } \\
\text { destruição da escola }\end{array}$ & $\begin{array}{l}\text { Insatisfações/falhas acompanhadas de desejo de } \\
\text { destruição }\end{array}$ & 13 \\
\hline $\begin{array}{l}\text { Breves momentos e situa- } \\
\text { ções de prazer e satisfação }\end{array}$ & $\begin{array}{l}\text { Satisfação com algumas matérias, aulas de educa- } \\
\text { ção física, aulas livres, férias }\end{array}$ & 8 \\
\hline $\begin{array}{l}\text { Anseios como sugestões } \\
\text { para a escola ser melhor }\end{array}$ & $\begin{array}{l}\text { O que a escola deveria ter: segunda-feira, educa- } \\
\text { césica, nada de matemática, português; quinta- } \\
\text { feira: só artes, desenhos; deveria ter rosas e não } \\
\text { espinhos; tinha que ter decoração bonita }\end{array}$ & 4 \\
\hline
\end{tabular}

significações dos dois quadros analisados mostra a contradição entre a escola que não serve para nada e a escola que salva!

No quadro 3, apresentam-se os indicadores que se agruparam sob a categoria temática Como Seria Não Ir à Escola e os núcleos de significação que puderam ser apreendidos das expressões dos participantes.

Não ir à escola tem, ao mesmo tempo, um sentido positivo e um sentido negativo para os sujeitos, que se dividiram igualmente a respeito dessa possibilidade. As avaliações negativas não deixam dúvida quanto aos riscos e prejuízos por não ir à escola. Já entre os que se animaram com a possibilidade de não ir, há os que não têm dúvida e os que titubeiam, mas mesmo assim afirmam que seria mais ou menos bom não ter que ir à escola.

As dúvidas sobre o assunto denotam o alto peso das críticas à escola, não se tratando apenas de uma questão do desejo do aluno, pois conhecem as consequências de sua escolha. Em uma sociedade excludente como a nossa, os jovens percebem que precisam do estudo e do diploma para tentar se livrar de um futuro incerto, para conseguir empregos dignos, não podendo abrir mão da escola, por pior que ela esteja.

No quadro 4, apresentam-se os indicadores das associações que fizeram a partir da palavra escola.

As evocações negativas, em maior número (13 indicadores), referem-se ao que não agrada ao aluno, ou à situação de fracasso da escola, acompanhadas por desejo de destruição. Em relação às significações positivas, referem poucas disciplinas, breves momentos mais livres e situações em que ocorre um descanso das lições, o que Ihes agrada, e sugerem anseios de como a escola poderia ser melhor.

Tal ambivalência reforça a ambiguidade presente nas falas e nas formas de expressão dos sujeitos desde o início da pesquisa. Vygotsky, de acordo com Oliveira (1996), propõe uma visão global do ser humano, indicando as necessidades, os interesses, os impulsos, os afetos e as emoções como fundamentais na vida e na conduta de uma pessoa.

Os indicadores nesta categoria temática sugerem que os participantes anulam suas expectativas em relação ao aprender e expõem sentimentos e soluções ambíguas que contrariam seus interesses, necessidades e afetos. A significativa insatisfação com a escola sugere que os alunos expõem uma ferida aberta, confirmando as críticas de Patto (1990) a respeito do caráter excludente da escola pelo distanciamento entre o que ela propõe e os anseios da população que a frequenta.

No quadro 5 , apresentam-se os indicadores que integraram a categoria temática Cotidiano da Escola e das Práticas Pedagógicas.

Em relação às práticas pedagógicas, é grande o número de indicadores (50) que fazem referência às cópias e lição de casa excessivas. Os alunos alegam cansaço, que denota um esvaziamento dos conteúdos no fazer sem fazer. Também se destacam as 23 referências à baixa qualidade do que circula no interior da escola e à forma como ela é conduzida e gerenciada, pelo excesso de aulas vagas e pela baixa qualidade dos materiais e do trabalho dos professores. 
Quadro 5. Cotidiano da escola e das práticas pedagógicas.

\begin{tabular}{|l|l|l|}
\hline Núcleos de significação & Indicadores & N \\
\hline $\begin{array}{l}\text { Esvaziamento dos conteúdos } \\
\text { pelas práticas pedagógicas }\end{array}$ & Cópias excessivas e muita lição de casa & 50 \\
\hline $\begin{array}{l}\text { Gerenciamento negativo } \\
\text { pelos agentes educativos }\end{array}$ & $\begin{array}{l}\text { Aulas vagas, qualidade dos materiais e qualidade } \\
\text { do trabalho dos professores }\end{array}$ & 23 \\
\hline
\end{tabular}

Quadro 6. Sobre os agentes institucionais.

\begin{tabular}{|c|c|c|}
\hline $\begin{array}{l}\text { Sub-categorias/Núcleos de } \\
\text { significação }\end{array}$ & Indicadores & $\mathbf{N}$ \\
\hline $\begin{array}{l}\text { Sobre o professor: } \\
\text { Ambivalência entre amor e } \\
\text { ódio em relação ao professor }\end{array}$ & $\begin{array}{l}\text { Expressões decorrentes do gosto pessoal do aluno } \\
\text { em relação ao professor }\end{array}$ & 26 \\
\hline Abuso de poder & $\begin{array}{l}\text { Professores não aguentam a situação e apelam } \\
\text { para o desrespeito e o autoritarismo }\end{array}$ & 24 \\
\hline $\begin{array}{l}\text { Ambivalência na qualidade } \\
\text { do trabalho do professor }\end{array}$ & $\begin{array}{l}\text { Expressões ambivalentes quanto ao domínio do } \\
\text { conteúdo e à qualidade do que e como ensinam }\end{array}$ & 11 \\
\hline $\begin{array}{l}\text { Sobre o diretor: } \\
\text { Qualidade do trabalho }\end{array}$ & Ineficiente, injusto, chato & 5 \\
\hline Abuso de poder & $\begin{array}{l}\text { Não respeita o aluno, não confia, vive chamando } \\
\text { os pais }\end{array}$ & 3 \\
\hline $\begin{array}{l}\text { Sobre o inspetor de alunos } \\
\text { Ambivalência no reconhe- } \\
\text { cimento do trabalho do } \\
\text { inspetor }\end{array}$ & São injustos, mas mantêm a ordem & 2 \\
\hline $\begin{array}{l}\text { Sobre o aluno } \\
\text { Culpabilização de si próprios } \\
\text { pelo fracasso da escola }\end{array}$ & $\begin{array}{l}\text { Transgridem as regras, não respeitam professo- } \\
\text { res e funcionários, não deixam a escola boa, não } \\
\text { gostam de algumas aulas }\end{array}$ & 7 \\
\hline
\end{tabular}

A despeito da literatura que patologiza a pobreza e culpabiliza o indivíduo e sua família por suas falhas, os alunos apresentaram outros argumentos para o fracasso escolar. Referiram o pouco investimento do professor, os materiais não adequados, a dinâmica da aula não favorecedora da aprendizagem e o distanciamento afetivo do professor com o aluno e com o objeto de conhecimento.

O professor chega, manda abrir o caderno, pega o giz, alguns não falam nem boa tarde, já começa a passar lição. Temos que copiar tanta lição que a mão fica doendo. Nós não temos aula porque às vezes eles não falam nada, só dá lição, manda copiar a página e ficamos copiando no caderno, é muito chato, dói o braço.

No quadro 6, incluem-se os indicadores referentes aos professores, diretores, inspetores e aos próprios alunos, agrupados na categoria temática Agentes Institucionais, com sub-categorias específicas a cada agente e respectivos núcleos de significações que puderam ser apreendidos.

Constatam-se 61 referências ao(s) professor(es) ao longo de toda a pesquisa, das quais 26 expressam o caráter ambivalente entre amor e ódio que nutrem pelos professores e 24 respostas concretizam a visão que os jovens têm de seus professores como sendo desrespeitosos, autoritários e que não aguentam as situações. A fala a seguir exemplifica o que eles entendem por atitude autoritária como defesa contra uma situação que não aguentam:

E tem professor que se você falar assim, ela pega e já põe falta; manda fazer tudo de qualquer jeito. Depois que a gente faz, ela fica reclamando, chama nossa mãe; é, eles não aguentam, não aguentam, não aguentam.

Onze respostas referem-se à baixa qualidade do trabalho do professor em relação ao domínio do conteúdo e à forma como ensinam:

(...) aí vem um professor que não sabe nem quanto é um mais um; é, tem uns que escrevem um monte de coisa errado lá [Erram] e dizem que é só pra ver se a gente tava prestando atenção; dizem que a gente não presta atenção. 
Quadro 7. Visão dos colegas e dos pais sobre a escola.

\begin{tabular}{|l|l|c|}
\hline Núcleos de significação & Indicadores & N \\
\hline $\begin{array}{l}\text { Quem está fora do ambiente } \\
\text { escolar qualifica a escola }\end{array}$ & Para os pais, a escola é boa & 9 \\
\hline $\begin{array}{l}\text { Quem está dentro do ambien- } \\
\text { te escolar critica a escola }\end{array}$ & Para os colegas, ela é ruim & 5 \\
\hline
\end{tabular}

Quadro 8. Condições sociais

\begin{tabular}{|l|l|c|}
\hline Núcleos de significação & Indicadores & N \\
\hline $\begin{array}{l}\text { Descaso das autoridades } \\
\text { políticas com a escola }\end{array}$ & $\begin{array}{l}\text { Falta de equipamentos, desvio de verbas, respon- } \\
\text { sabilização dos políticos }\end{array}$ & 9 \\
\hline $\begin{array}{l}\text { Preconceito entre classes } \\
\text { sociais }\end{array}$ & $\begin{array}{l}\text { Oposição entre escola particular e pública; entre } \\
\text { ricos e pobres }\end{array}$ & 3 \\
\hline
\end{tabular}

Considerando-se o valor do papel mediador do professor no favorecimento das aprendizagens dos alunos, apreende-se dessas falas que a distância entre o professor e o aluno abre um fosso, afastando o aluno de uma real aproximação com o conhecimento. Não se trata, no entanto, de culpabilizar o professor pelas dificuldades de aprendizagem do aluno ou pelo fracasso da escola.

Concorda-se com Sawaia (2002) que

É no sujeito que se objetivam as várias formas de exclusão, a qual é vivida como motivação, carência, emoção e necessidade do eu. [...] É o indivíduo que sofre, porém esse sofrimento não tem a gênese nele, e sim em intersubjetividades delineadas socialmente (p. 98-99).

Esse fosso aberto e que parece manter alunos e professores segregados, como também os demais agentes institucionais (diretores e inspetores), é confirmado pelas autorreferências de uma conduta inadequada por alunos, fechando um ciclo que se autossustenta:

Não respeitamos os professores. Os funcionários, eu os irrito e saio correndo. Eu adoro irritar as pessoas.

(...) os alunos não deixam ela [a escola]boa, eles pioram a situação.

Isso confirma dados de outras pesquisas, como a de Souza (2009), cujos resultados mostram o desrespeito como valor negativo que, ao circular na escola, é apropriado pelos sujeitos nas interações - alunos, professores e equipe técnica -, constituindo-se como um conjunto de atitudes de uma dinâmica aversiva, desrespeitosa e desgastante: "o espaço e tempo da aula transformam-se no cenário das lutas e embates que consomem o que deveria ser o tempo do ensino e da aprendizagem" (p. 134-135).
Resta saber qual o avanço possível em direção a um desenvolvimento prospectivo, na perspectiva vigotskiana, quando os envolvidos ficam aprisionados em um espaço reduzido pelos embates e, provavelmente, subtraídos no que tange à construção do conhecimento e à liberação de carga afetiva e volitiva positivas.

No quadro 7, apresentam-se os indicadores relativos à visão que os pais e os colegas têm da escola, segundo os participantes da pesquisa. Tais conteúdos integram a categoria temática denominada Visão do Outro (pais e colegas) sobre a Escola, sendo que as significações são construídas pelos sujeitos a partir de uma visão de fora, no caso dos pais, e de dentro, no caso dos colegas.

Os colegas, no caso, são os próprios alunos que vivem a mesma situação e têm igualmente críticas à escola. Já os pais, talvez pela maioria não ter terminado os estudos, depositam na escolarização dos filhos a esperança de um futuro melhor que o seu. Ou seja, os participantes mostram saber que seus pais valorizam a escola, independente do que ela é na realidade. Para Lahire (1997, p. 334-335), a maioria dos pais vê a escola como algo importante e tem a esperança de ver os filhos "saírem-se" melhor do que eles; almejam, para sua progênie, um trabalho menos cansativo, menos sujo, menos mal-remunerado, mais valorizador do que o deles, mesmo nos casos em que as rupturas são numerosas e as condições de vida difíceis, colocando suas disposições sociais e condições familiares a mil léguas das disposições e das condições necessárias para ajudar as crianças a "ter êxito" na escola.

Finalmente, o quadro 8 mostra os indicadores agrupados na categoria temática Visão das Condições Sociais, cujos núcleos de significação tangenciam as questões macroestruturais, éticas e sociais que permeiam a escola construídas pela análise, como descaso de autoridades e preconceito social.

Dentre os indicadores, constatam-se nove referências em relação à falta de equipamentos, desvio de verbas 
e descaso das autoridades políticas em relação à escola e três relacionadas ao preconceito que percebem haver entre as classes sociais, que separa ricos e pobres em escolas diferentes. Talvez esses dados possam ser referidos à população de que se trata, todos pertencentes a uma comunidade cujas lideranças vêm lutando, a partir dos anos 1990, por garantir educação de qualidade. Os alunos assinalam que não são iguais, não têm direitos iguais e tampouco são respeitados, e isso gera um sentimento de raiva daqueles com melhores condições sociais. Referem que os políticos deveriam oferecer condições adequadas, mas percebem que, em uma sociedade dividida em classes, só quem tem condições de pagar tem direito à educação de qualidade. Pelas falas, apreende-se o risco de uma autodepreciação como consequência da percepção de desigualdade de condições entre os que frequentam a escola pública e os que frequentam a escola particular.

\section{Considerações Finais}

Os participantes deste estudo, crianças e jovens na faixa etária dos 10 aos 13 anos, são provenientes de um contexto marcado pela pobreza, violência e desemprego (ou subemprego). Tais características configuram o perfil de suas famílias, submetidas a condições objetivas determinantes das reais possibilidades de sua inserção social, na visão de Bourdieu (1999). Desprovidas de condições materiais para o acesso a bens culturais e simbólicos, criando seus filhos no espaço de uma comunidade emergente em grande centro urbano como São Paulo, depositam na escola a esperança de um futuro melhor para eles.

Esses anseios são nitidamente apreendidos em diferentes momentos da coleta de dados. A escola é percebida pelos participantes como necessária e feita para o aluno aprender, se promover, conseguir emprego e ser alguém na vida. No entanto, muitas das significações negativas em relação a ela, ao cotidiano vivido, às práticas educacionais e aos relacionamentos interpessoais sugerem que ela não está funcionando como deveria, tampouco como gostariam.

Vários aspectos negativos são apontados: aulas vagas e sem sentido, muita cópia, falta de materiais adequados, falta de professores, professores que não conseguem dar aula nem manter a ordem, autoritarismo, desrespeito e falta de investimento público. Poucos conseguem apontar aspectos agradáveis, como as aulas de educação física, de educação artística, as férias e alguns professores e aulas que apreciam como positivas.

Em relação à suspeita de uma resistência à escola por parte dos alunos, como resposta de reciprocidade à resistência da escola em relação aos alunos, ela se confirma. Os sujeitos não esconderam o desafeto pelos professores e pelos agentes institucionais. Afirmam não serem respeitados e reagem com a falta de respeito.

Os alunos da pesquisa sugerem que os professores não aguentam as condições de trabalho e nem todos ensi- nam como eles gostariam. Ao ir à escola, depositam nela a esperança de um futuro melhor, mas não conseguem aprender, e acabam por desenvolver atitudes negativas em relação à escola e aos professores, colaborando para a aula não acontecer.

Todos os participantes da pesquisa frequentam a escola, o que é indicativo de que, de fato, são beneficiários da expansão de vagas. O que chama a atenção, no entanto, é a consideração negativa dos processos educacionais vividos por esses jovens, aliada ao sentimento de rejeição social e desqualificação. De acordo com Campos (2003), a tensão da qual se reveste a exclusão (daqueles que frequentam a escola e não aprendem) se dá pelo contraste com a inclusão social, que "traz consigo significados simbólicos de perda de identidade, de não pertinência ou desfiliação, de negação de acesso" (p. 186). Não por acaso, são esses os sentimentos trazidos pelos participantes desta pesquisa.

$\mathrm{Na}$ busca de respostas para as questões norteadoras desta pesquisa, novas perguntas se abrem: O que poderia romper com este círculo vicioso de representações e ações cristalizadas? Quais as possibilidades de os agentes institucionais construírem outras relações e condições para a aprendizagem e outros espaços de diálogo e de parceria na construção do conhecimento? Diante desse fragmento da realidade, quais ações caberiam?

A construção de uma escola condizente com o que a sociedade espera dela é um longo e complexo processo, no qual muitas variáveis ou fatores estão implicados. Embora não seja possível uma generalização, os resultados sugerem que a construção de um ambiente efetivamente democrático no interior da escola demanda um esforço coletivo. Tal construção não será apenas fundamentada em posições e disposições sociais, como sugere Lahire (1997), mas poderá depender das aproximações entre os agentes educacionais e as famílias, do investimento público em educação de qualidade, da gestão social e da integração efetiva dos meios populares nos programas educacionais, enfim, da mobilização de um papel pró-ativo de todos os envolvidos em favor não só da educação para todos, mas da qualidade da educação para todos.

A visão dos sujeitos pesquisados aponta para a dificuldade da escola em lidar com a diversidade e as diferenças, o que resulta em um desencontro entre seus agentes e seus usuários. No entanto, os resultados também sugerem que a efetiva criação de condições de igualdade e legitimidade no acesso a uma educação de qualidade traria sentimentos mais positivos e satisfação por parte dos usuários, desde que resultassem em processos educacionais mais significativos.

Sugere-se a continuidade de estudos dessa natureza, que abrem a possibilidade de expressão dos sujeitos e de escuta a respeito da realidade vivida. Sobretudo, em pesquisas como essa, seria necessário incluir também a visão dos professores e dos pais como participantes ativos dessa e nessa mesma realidade. 


\section{Referências}

Aguiar, W. M. J. (2002). A pesquisa em Psicologia Sócio-Histórica: contribuições para o debate metodológico. Em A. M. B. Bock, M. G. M. Gonçalves \& O. Furtado (Orgs.), Psicologia Sócio-Histórica: uma perspectiva crítica em psicologia ( $2^{a}$ ed., pp. 1-29). São Paulo: Cortez.

Aguiar, W. M. J., \& Ozella, S. (2006). Núcleos de significação como instrumento para a apreensão da constituição dos sentidos. Psicologia: ciência e profissão, 26(2), 222-245.

Althusser, L. (1974). Ideologia e Aparelhos Ideológicos de Estado. Lisboa: Ed. Presença.

Bardin, L. (1977). Análise de conteúdo. Lisboa: Edições 70.

Bleger, J. (1966). Psicohigiene y Psicología Institucional. Buenos Aires: Ed. Paidós.

Bleger, J. (1976). Temas de Psicología - entrevista y grupos $\left(6^{a}\right.$ edición). Buenos Aires: Nueva Vision.

Bock, A. M. B, Gonçalves, M. G. M, \& Furtado, O. (Orgs.). (2001). Psicologia Sócio-Histórica: uma perspectiva crítica em psicologia. São Paulo: Cortez.

Bourdieu, P. (1972). Structures, habitus et pratiques. Em P. Bourdieu, Esquisse d'une théorie de la pratique. Paris, Genéve: Droz.

Bourdieu, P. (1999). A escola conservadora: as desigualdades frente à escola e à cultura. Em M. A. Nogueira \& A. Catani (Orgs.), Pierre Bourdieu: Escritos de Educação (2ª ed., pp. 37-64) (A. J. Gouveia, Trad.). Petrópolis, RJ: Vozes. (Trabalho original publicado em 1966)

Bourdieu, P., \& Champagne, P. (1999). Os excluídos do interior. Em M. A. Nogueira \& A. Catani (Orgs.), Pierre Bourdieu: Escritos de Educação (2a ed., pp. 217-227) (M. de Castro, Trad.). Petrópolis, RJ: Vozes. (Trabalho original publicado em 1992)

Cagliari, L. C. (1997). O príncipe que virou sapo - considerações a respeito das dificuldades de aprendizagem das crianças na alfabetização. Em M. H. S. Patto, Introdução à Psicologia Escolar (3a ed., pp. 193-224). São Paulo: Casa do Psicólogo.

Campos, M. M. (2003). Educação e políticas de combate à pobreza. Revista Brasileira de Educação, 24, 183-191.

Davis, C., \& Silva, F. G. (2004). Conceitos de Vigotski no Brasil: produção divulgada nos Cadernos de Pesquisa. Cadernos de Pesquisa, 34, 123-140.

Departamento Intersindical de Estatística e Estudos Socioeconômicos - Dieese (2002). Cesta Básica - posição em dezembro de 2002. Recuperado: 29 out. 2008. Disponível: http://www.condsef.org.br/ links_f_ut_dieese.htm.
Ferrari, A. R. (1999a). Alfabetização e escolarização de crianças e adolescentes no Brasil: um diagnóstico. Porto Alegre: Relatório de Pesquisa CNPq.

Ferrari, A. R. (1999b). Diagnóstico da escolarização no Brasil. Revista Brasileira de Educação, (12) 22-47.

Freitas, M. T. A. (2000). Vygotsky e Bakthin - Psicologia e Educação: um intertexto ( $4^{\mathrm{a}}$ edição). São Paulo: Editora Ática.

Gatti, B. (2004). Estudos quantitativos em educação. Educação e Pesquisa, 30(1), 11-30.

Gomes, C. A. (2002). Planos de papel e planos realizadores: a diferença do pacto educacional. Em C. A. Gomes, Traduzindo em ações o Plano Nacional de Educação (pp. 199-208). Brasília: UNESCO e Comissão de Educação do Senado Federal.

Gomes, C. A. (2004). Quinze anos de ciclos no ensino fundamental: um balanço das pesquisas sobre a sua implantação. Revista Brasileira de Educação, 25, 39-52.

Instituto Brasileiro de Geografia e Estatística. (2000). Censo demográfico do Ipiranga, Cursino e Sacomã. São Paulo: Instituto Brasileiro de Geografia e Estatística.

Kohl, M. (1996). Escolarização e organização do pensamento. Revista Brasileira de Educação, 3, 97-102.

Lahire, B. (1997). Sucesso escolar nos meios populares: as razões do improvável. São Paulo: Ática.

Lane, S. T. M., \& Camargo, D. (1995). Contribuições de Vigotski para o estudo das emoções. Em S. T. M. Lane \& B. B. Sawaia (Orgs.), Novas veredas da psicologia social (pp. 115-131). São Paulo: Brasiliense.

Lapassade, G. (1977). Grupos, organizações e instituições. Rio de Janeiro: Francisco Alves.

Mainardes, J. (1998). A promoção automática em questão: argumentos, implicações e possibilidades. Revista Brasileira de Estudos Pedagógicos, 192(79), 16-29.

Mainardes, J. (1999). Cenários de aprendizagem: instâncias interativas na sala de aula. Em J. B. Martins (Org.), Na perspectiva de Vygotsky (pp. 81-102). São Paulo: Quebra Nozes.

Marinho-Araújo, C. M. e cols. (Orgs.) (2009). Psicologia Escolar: novos cenários e contextos de pesquisa, formação e prática. Campinas, SP: Alínea.

Meira, M. E. M., \& Antunes, M. A. M. (Orgs.). (2003). Psicologia Escolar: teorias críticas. São Paulo: Casa do Psicólogo.

Mello, G. N. (1979). Crescimento da clientela escolar e democratização do ensino: uma questão de definir a quem beneficiar prioritariamente. Cadernos de Pesquisa, (28) 49-51. 
Mello, G. N. (1981). Ensino de $1^{\circ}$ grau: direção ou espontaneismo. Cadernos de Pesquisa, (36), 87-91.

Oliveira, M. K. (1996). Escolarização e organização do pensamento. Revista Brasileira de Educação, (3), 97-102.

Oliveira, M. K., Souza, D. T. R., \& Rego, T. C. (Orgs.). (2002). Psicologia e Educação e as temáticas da vida contemporânea. São Paulo: Moderna.

Ozella, S., \& Sanches, S. G. (2002). Breve histórico do desenvolvimento da pesquisa na perspectiva sócio-histórica. Em Bock, A. M. B.; Gonçalves, M. G. M.; Furtado, O. (Orgs.), Psicologia Sóciohistórica: uma perspectiva crítica em psicologia (pp. 141-158). São Paulo: Cortez.

Patto, M. H. S. (1981). Introdução à Psicologia Escolar. São Paulo: T. A. Queiroz.

Patto, M. H. S. (1984). Psicologia e ideologia:uma introdução crítica à Psicologia Escolar. São Paulo: T. A. Queiroz.

Patto, M. H. S. (1990). A produção do fracasso escolar: histórias de submissão e rebeldia. São Paulo: T. A. Queiroz.

Rey, F. G. (2002). Pesquisa qualitativa em Psicologia: caminhos e desafios. São Paulo: Pioneira Thomson Learning.
Sawaia, B. (2002). O sofrimento ético-político como categoria de análise da dialética exclusão/inclusão. Em B. Sawaia (Org.), As artimanhas da exclusão: análise psicossocial e ética da desigualdade social. (4ª ed., pp. 97-118). Petrópolis, RJ: Vozes.

Snyders, G. (1981). Escola, classe e luta de classes (2 $\left.{ }^{\mathrm{a}} \mathrm{Ed}\right)$. Lisboa: Moraes.

Souza, V. L. T. (2009). Educação, valores e formação de professores: contribuições da psicologia escolar. Em C. M. Marinho-Araújo e cols. (Orgs.), Psicologia Escolar: novos cenários e contextos de pesquisa, formação e prática (133-151). Campinas, SP: Editora Alínea.

Tanamachi, E. R., Souza, M. P. R., \& Rocha, M. L. (Orgs.). (2002). Psicologia e Educação: desafios teórico-práticos ( $2^{\mathrm{a}}$ ed.). São Paulo: Casa do Psicólogo.

Vigotski, L. S. (1998a). Pensamento e linguagem (J. L. Camargo, Trad.) ( $2^{a}$ edição). São Paulo: Martins Fontes. (Trabalho original publicado em 1934)

Vigotski, L. S. (1998b). A formação social da mente (J. C. Neto, L. S. M. Barreto, S. C. Afeche, Trad.) (6ª edição). São Paulo: Martins Fontes.
Recebido em: 29/8/2009

Reformulado em: 23/6/2010 (1 $\left.{ }^{\mathrm{a}}\right)$

Reformulado em: 20/10/2010 (2a)

Aprovado em: 21/01/2011

\section{Sobre as autoras}

Patrícia Batista Marques (paty.lynda@hotmail.com)

Universidade São Marcos, São Paulo, SP

Marisa Irene Siqueira Castanho (msiqueiracastanho@gmail.com)

Centro Universitário Fieo - UNIFIEO, Osasco - SP.

\section{Endereço para correspondência:}

Rua Loreto, 61 - ap. 81, Vila Santo Estéfano - CEP. 04152-130 - São Paulo - SP.

Informações complementares: Natureza do trabalho - relato de pesquisa de Iniciação Científica desenvolvida durante o $9^{\circ}$ e o $10^{\circ}$ semestre do curso de Graduação em Psicologia da Universidade São Marcos, no período 2005-2006 